\title{
Gray Wolf Prey Base Ecology in the North Fork of the Flathead River Drainage
}

\author{
C. Les Marcum + Daniel H. Pletscher + Michael Bureau \\ SCHOOL OF FORESTRY + UNIVERSITY OF MONTANA \\ Missoula
}

\section{$\downarrow$ INTRODUCTION}

The overall objective of this two-year investigation is to study gray wolf (Canis lupus): ungulate interrelationships in a multi-prey system. This study focuses on elk (Cervus elaphus), and is being conducted in the North Fork of the Flathead River drainage, in Montana and British Columbia, the main area of grey wolf recovery.

We address questions that resource managers will be asked as wolf recovery occurs. From a National Park Service perspective, the results could be used to educate the public about the role of predation in natural systems. Glacier National Park has the opportunity to lead the way in conducting research on this keystone predator and its prey, and to demonstrate the role biosphere reserves can play in ecological research.

Information that will be important for future informed resource management is being gathered. Management of public lands might require a balance accommodation between wolves, their prey, and sport hunting, along with other forms of recreation. The Montana Department of Fish, Wildlife, and Parks needs information on the impacts of wolves on game populations in order to maintain numbers and recreational opportunities. As reintroduction of wolves in Yellowstone National Park is considered and debated, knowledge gained from this study will be helpful.
Finally, this study can expand ecological knowledge of the role of a major predator on the prey population dynamics and interrelationships. To expand knowledge of the study area prey base available to wolves, these specific parameters will be addressed:

1. Age and cause-specific mortality of elk.

2. Seasonal distribution and key elk seasonal use areas.

3. Age, sex distribution/composition of the elk population.

4. Long-term elk abundance and distribution monitoring plan.

\section{$\downarrow$ Methods}

We are assessing cause-specific mortality for elk by using motion-sensitive radio transmitters (mortality collars). Collapsible traps modified (Sparrowe and Springer 1970, Roper et al. 1971, and McCullough 1975) from Clover's (1954) design are used to capture elk during winter. The traps are baited with second-cutting, weed-free alfalfa hay. We have placed the traps within the territory of the Camas Pack in Glacier National Park, and the Flathead National Forest. Traps are checked daily. When elk are captured, the trap is collapsed and the animal remains physically restrained. 
We secured mortality collars on yearlings and adult female elk. The collars are an inconspicuous color (brown and black) to satisfy the aesthetic concerns of Glacier Park rangers. Collars are monitored daily to determine whether the animal is still moving. When the received signal indicates that an animal has not moved for 4 hours, the animal is approached and the cause of mortality is determined (O'Gara 1978, Wobeser and Spraker 1980). Seasonal mortality rates will be determined for yearlings and adults following Heisey and Fuller (1985). A further mortality classification by age in years is not possible due to the small sample size.

Calf production and survivorship will be assessed during 1991 by locating each cow aerially or by foot and looking for a calf. Visuals will begin during the second week of May and continue monthly throughout the summer. Cows that are identified as productive will be visually located once a month, while cows without calves will be visually located every two weeks until the third week of June at which time they will be assumed to be non-productive.

Bear scat were collected as in the past by McLellan, and the proportion of the scats containing elk remains will be determined. The proportion of elk remains in a wolf diets will be determined by the Wolf Ecology Project using scat analysis from feces collected at den and rendezvous sites. Hair from calves and adults will be identified separately, and regression equations (Floyd et al. 1978), modified by J. Weaver (pers. commun.) will be used to estimate the proportion of calves in the diet at that time.

Radio-collared animals are relocated weekly to identify key areas of seasonal use and seasonal movements. Locations are determined from the ground whenever possible, and from aircraft when necessary. The Universal Transverse Mercator system of recording locations is used to insure that these locations can be used in a geographical information system. Areas receiving high seasonal use, as indicated both by radio locations and by pellet counts (see below), will be identified.

Age and sex composition will be estimated when elk are aerially located during winter (Unsworth and Kuck 1988). Males continue to carry their antlers until the end of the winter and can be identified as such. Calves can be identified by size and by shape of the head. The sex and age composition of elk populations will also be estimated from road-side counts. Both elk and deer tend to concentrate along the North Fork River in spring, making this the time when elk are most observable from the ground. This may not be a representative count of males and females but, if used for a number of years, should indicate trend. Cow-calf counts should be representative of the population.

Pellet group counts (Neff 1968) will be used as an index to estimate relative elk abundance. Transects have been set up in cooperation with concurrent white-tailed deer (Odocoileus virginianus) and moose (Alces alces) studies, following a stratified random sampling scheme (Freddy and Bowden 1988). Results from other studies conducted in the same area, were used to estimate the sample size needed to detect a $20 \%$ change in population with $95 \%$ probability. These indices of abundance can continue to be obtained after this project is complete.

Roadside counts, described above to monitor population composition, will also be used with location data to estimate population size. The number of radio collared elk seen will be used in conjunction with the number of radio collared animals in the area and the total number of elk seen to estimate population size using the Petersen Index (Caughley 1977). Flights in early winter will further aid to form an index of abundance.

\section{$\downarrow \quad$ Results ANd Discussion}

Trapping of elk began in early January and continued until early April. Due to unusually heavy snowfall and a subsequent shift in habitat use by elk, only 16 cow elk were successfully collared (Fig. 1 for age distribution). Of these, two cows of ages 8 and 12

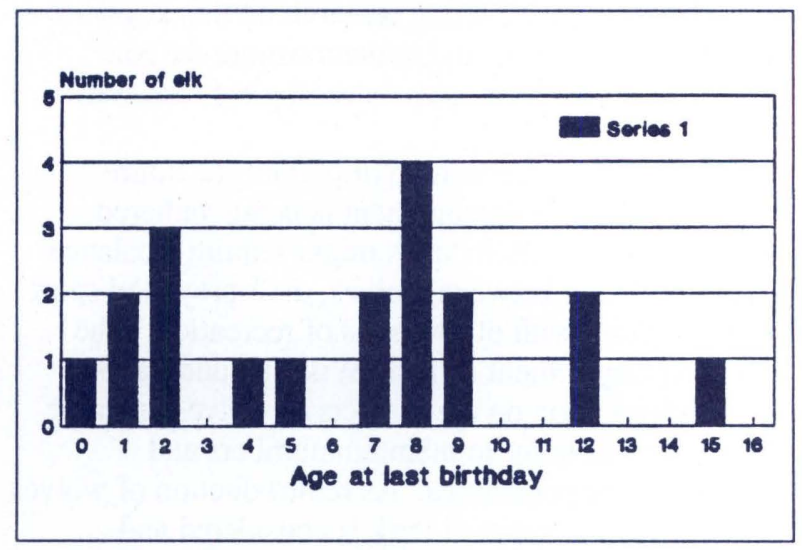

Figure 1. Age distribution of captured elk 
yr were killed by mountain lions (Felis concolor). One cow died a week after capture of what is suspected to be Pasteurella-related pneumonia. Tissues were collected and sent to the Montana State Veterinary Diagnostic Laboratory for analysis. Three elk died as a direct result of trapping. One was a calf, and the other two cows were the oldest of those captured at 12 and $15 \mathrm{yr}$. The latter two also exhibited streaked livers indicating recent infection ( $\mathrm{O}^{\prime} \mathrm{Gara}$, pers. comm.). A meeting was held on March 31, 1990 with representatives from Glacier National Park, Montana Fish, Wildlife, and Parks, U.S. Fish and Wildlife Service, and U.S. Forest Service to determine whether trap mortalities could have been prevented. It was decided that in all but possibly one case, they were not preventable. Trapping was terminated when it was judged that the elk were no longer in condition for safe capture. Trapping will resume December 1990 and continue until the desired sample size of 30 animals is reached. We believe trapping the remaining elk will be mucheasier due to our advanced knowledge of winter distribution and movements from this past season.

A pellet count sampling plan has been constructed with accuracy, precision, and efficiency in mind. Field work began April 22, 1990 and was completed by June
1, 1990. The data have not yet been analyzed.

Roadside counts of elk have also begun along the North Fork River. Flights were begun in May along the river corridor to visually estimate elk abundance, and herd composition. Due to poor weather, small numbers of elk seen, and inability to distinguish antlerless males from females, it was decided to move the aerial surveys to early winter when elk congregate in large numbers in open meadows and males are readily distinguished from females. Early winter flights will probably be in conjunction with Montana Department of Fish, Wildlife, and Parks, which is planning to initiate its own aerial surveys in the North Fork this winter. Radiotracking and mortality monitoring will continue until late summer, 1991. As of September 1, 1990 over 300 aerial and ground locations of elk have been recorded on summer and winter ranges and migration routes. Of 13 collared elk alive, 10 migrated into British Columbia to summer ranges, two stayed in the Whitefish Range in Montana, and one is unaccounted for, presumably due to a malfunctioning collar (see Fig. 2). Four of the collared elk summered near a proposed coal mine in the Cabin Creek drainage of B.C. Winter locations are ground triangulations, while summer locations are obtained during a mix of aerial and ground radio locations.

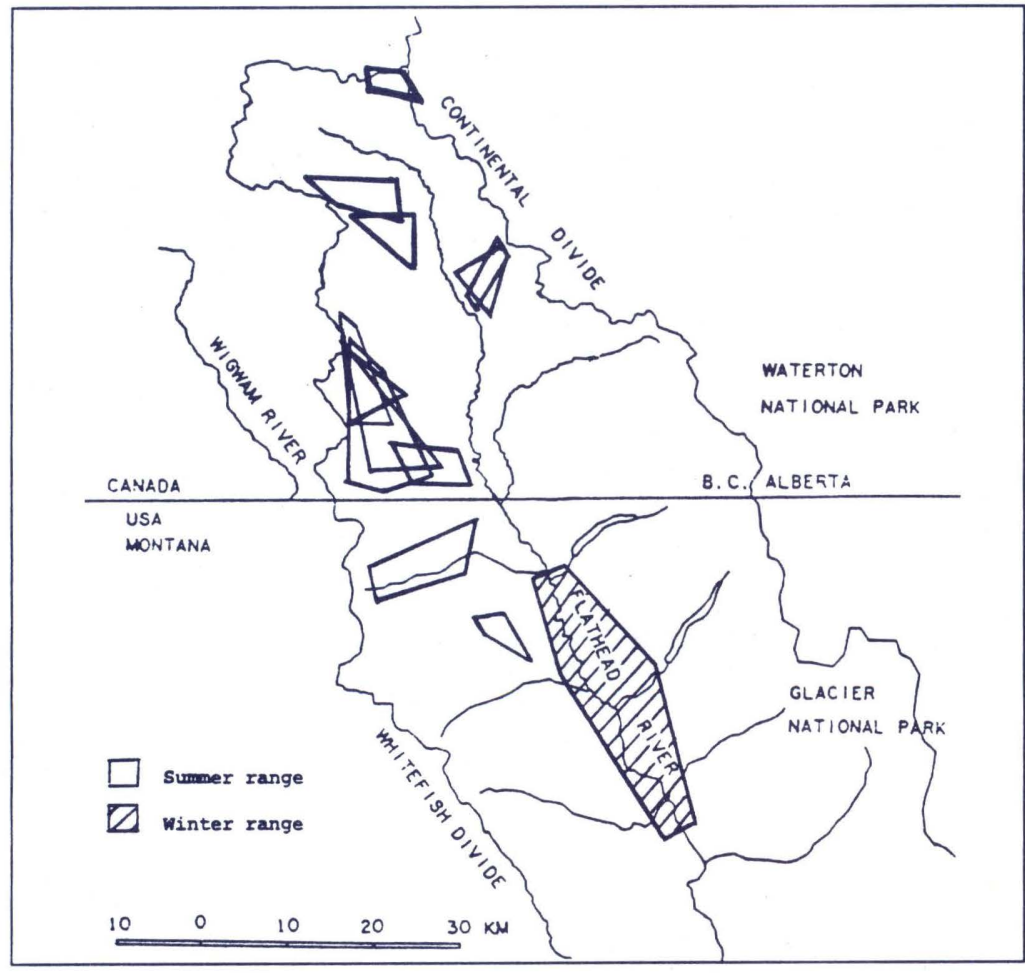

Figure 2. Seasonal distribution of collared elk.
Location data have not yet been analyzed, but initial examination of the data indicate that elk made extensive use of Big Prairie and other open meadows in early winter until the snowpack crusted over. At this point, elk moved into timber until spring thaw softened the snow crust. The Red Bench Fire area was heavily used by elk in the Akokala region, probably for aspen (Populus tremuloiodes) shoots and other fire-related vegetation. Migration began in late April and was complete by July, 1990. Elk began stabilizing their movements as early as 1 June, but after a week of hot weather at the end of June, many elk moved to higher ranges. The elk that did not move typically occupied steep, narrow ravines along riparian zones. During July and August elk were often seen lying on snowbanks in alpine cirques. Many were also located near mineral licks during this time. Cow/calf ratio as of September 1, 1990 was estimated to be $2: 1$. Cow/bull ratios during this period are assumed to be unrepresentative. 


\section{$\downarrow \quad$ Conclusions}

Results to date indicate that management of North Fork elk must be interagency and international. Twelve of the 13 elk captured on winter range in Glacier National Park, may soon be subject to hunting in British Columbia and Montana. We hope to trap elk wintering south of Big Prairie this winter in order to find additional summer range areas within and outside Glacier National Park. A large number of the North Fork elk winter on Big Prairie and surrounding areas, and we brlieve that park management actions, i.e. fire control, affect the elk. Management of the elk herd to account for wolf predation must include British Columbia agencies; Montana Department of Fish, Wildlife, and Parks; U.S. Forest Service; and Glacier National Park.

No predation by wolves of collared elk has occurred thus far. Lions have killed two elk, indicating that they are a predator of elk. Because of this, we will backtrack lions this winter to find more kills to better understand the effects of this predator on the elk. Data on herd size and composition will be collected early this winter.

\section{$\downarrow$ Summary}

The four goals of this study of the elk (Cervus elephus) inhabiting the North Fork of the Flathead River drainage are to determine 1) age and cause-specific mortality, 2) seasonal distribution and migration 3) age and sex composition, and 4) index to population change. Sixteen elk were captured using collapsible Clover traps and fitted with mortality collars during winter 1989-90. Two were killed by lions (Felis concolor) at ages 8 and $13 \mathrm{yr}$, and one died from infection. Over 300 elk locations using radiotelemetry have been collected on summer and winter ranges and migration routes. Spring aerial counts for estimating herd composition were found to be inadequate and were rescheduled to early winter. Cow/calf ratio as of September 1 was 2:1. Roadside counts and pellet transects have been conducted for an index to elk abundance, and aerial counts will begin in early winter 1990 .

\section{$\downarrow \quad$ Literature Cited}

Caughley, G. 1977. Analysis of vertebrate populations. John Wiley and Sons New York. $234 \mathrm{pp}$.

Clover, M. R. 1954. A portable deer trap and catch-net. Calif. Fish and Game 40:367-373.

Floyd, T. J., L. D. Mech, and P. A. Jordan. 1978. Relating wolf scat content to prey consumed. J. Wildl. Manage. 42:528-532.

Freddy, D. J., and D. Bowden. 1988. Sampling mule deer pellet-group densities in juniper-pinyon woodland. J. Wildl. Manage. 47:476-485.

Heisey, D. M., and T. K. Fuller, 1985. Evaluation of survival and cause-specific mortality rates using telemetry data. J. Wildl. Manage. 49:668-674.

McCullough, D. R. 1975. Modification of the Clover deer trap. California Fish and Game. 61:242-244.

Neff, D. J. 1968. The pellet group for big game trend, census, and distribution: a review. J. Wildl. Manage. 32:597-614.

O’Gara, B. W. 1978. Differential characteristics of predator kills. Pages 380-393 in Proc. 8th Biennial Pronghorn Antelope Workshop, Jasper, Alberta.

Roper, L. A., R. L. Schmidt, and R. B. Gill. 1971. Techniques of trapping and handling mule deer in northern Colorado with notes on using automatic data processing for data analysis. Proc. Western Assoc. Game and Fish Comm. 51:471-477.

Sparrowe, R. D., and P. F. Springer. 1970. Seasonal activity patterns of white-tailed deer in eastern South Dakota. J. Wildl. Manage. 34:420-431.

Unsworth, J. W., and L. Kuck. 1988. Elk ecology, Study III: Elk sightability. Idaho Dept. Fish \& Game, Project W-160-R-15. Job Progress Report.

Wobeser, G. A., and T. R. Spraker. 1980. Post-mortem examination. Page 89-98 in Schemnitz, ed. Wildlife management techniques manual. 4th ed. The Wildl. Soc., Washington, D.C. 